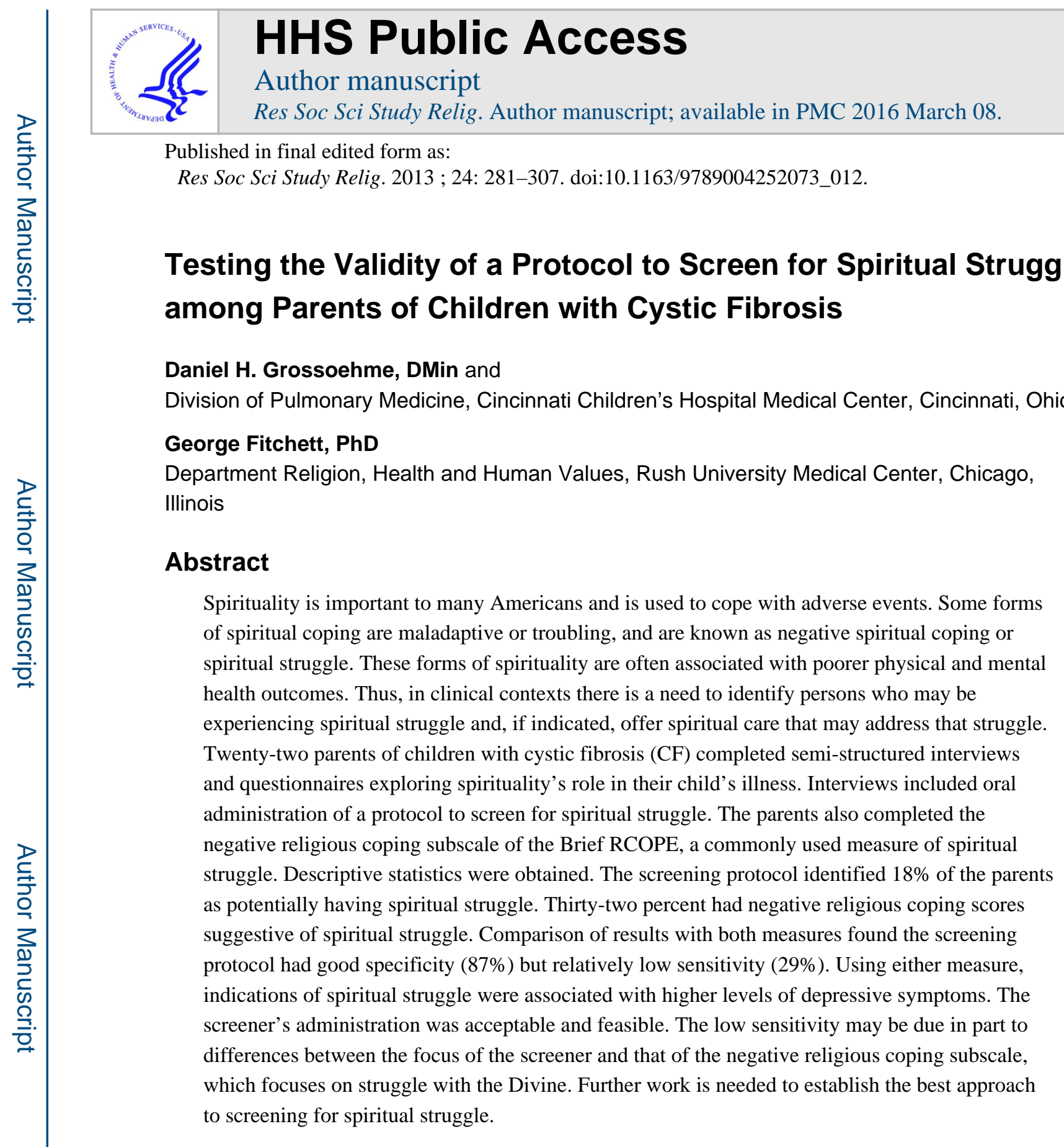

Spirituality and religion have been studied in relation to health for a considerable period of time, and numerous reviews have been published (Koenig, King, \& Carson, 2012; Pargament, 1997). Many studies have linked various dimensions of faith, including religiosity (Berman et al., 2004; Cotton, Puchalski, et al., 2006; Cotton et al., 2010), worship attendance (Chida, Steptoe, \& Powell, 2009), and spiritual coping with different health outcomes, both physical (K. I. Pargament, H. G. Koenig, N. Tarakeshwar, \& J. Hahn, 2001a) and mental (Pargament, Ellison, Tarakeshwar, \& Wulff, 2001; Pargament, Koenig, Tarakeshwar, \& Hahn, 2004). In general, spirituality and religion have been understood as beneficial for health.

Corresponding author: Daniel H. Grossoehme, DMin. Division of Pulmonary Medicine, Cincinnati Children's Hospital Medical Center, 3333 Burnet Avenue MLC2021, Cincinnati, OH 45229 USA. daniel.grossoehme@cchmc.org. 


\section{Negative Dimension of Spirituality}

While spirituality and religion are often assumed to have a positive role in life, there is a salient negative dimension. It appears that the negative dimension of spirituality and religion may also play a role in health (Fitchett et al., 2004). The negative dimension of spirituality has been associated with loss of recovery of independence among medically ill elderly (Fitchett, Rybarczyk, DeMarco, \& Nicholas, 1999), poorer physical health and quality of life, and increased depression (Koenig, Pargament, \& Nielsen, 1998), as well as mortality (Pargament, Koenig, et al., 2001a). Reviews of these and similar studies have published been elsewhere (Ano \& Vasconcelles, 2005; Exline \& Rose, 2005; Pargament, MurraySwank, Magyar-Russell, \& Ano, 2005). Spiritual struggle is understood as maladaptive spiritual thoughts about disease, illness or some other stressful event (Wortmann, Park, \& Edmondson, 2011). Stressful events or conditions cause one to appraise the threat level of the stressor; the resources one has to minimize or overcome the stressor; and finally, to use thoughts or behaviors in an attempt to utilize those resources against the stressor (Folkman, Lazarus, Dunkel-Schetter, DeLongis, \& Gruen, 1986). Drawing on the stress-coping model of Folkman and Lazarus, Pargament (1997) developed a model of spiritual and religious coping, defined as, "the search for significance, in times of stress, in ways related to the sacred" (Pendleton, Cavalli, Pargament, \& Nasr, 2002; p. 1). Pargament and colleagues (2000) identified various styles of spiritual coping, which can be broadly categorized as forms of control/problem-solving, constructing meaning, transforming one's life, or seeking comfort from other people or from God. Some styles are positive (e.g., "Seeking spiritual support"); others are negative (e.g., "Decided the Devil made this happen") because of their association with positive and negative health outcomes, respectively, rather than any connotation as to whether they are "good" or "bad" types of coping (Pargament, Koenig, \& Perez, 2000). Pargament (1997) states that persons may utilize more than one religious coping style for a given stressor, and indeed may employ both positive and negative religious coping styles simultaneously (for example, seeking a closer connection with God while wondering whether one's church had abandoned them;(Pargament, 1997). While maladaptive, negative spiritual coping styles are not identical to what has been termed "spiritual struggle," the construct of spiritual struggle is typically operationalized by studying negative religious coping (Ai, Pargament, Kronfol, Tice, \& Appel, 2010; Fitchett \& Risk, 2009; Pargament, 2008; Pargament, Feuille, \& Burdzy, 2011; Sherman, Simonton, Latif, Spohn, \& Tricot, 2005). In fact, Pargament and colleagues (2011, p. 55) refer to negative religious coping and spiritual struggle as "interchangeable" (Pargament, et al., 2011).

\section{Association of Spiritual Struggle with Health}

A number of studies have reported harmful emotional and physical effects associated with spiritual struggle. For example, a study of 160 adult women with breast cancer in the UK found that spiritual struggle, notably feeling punished or abandoned by God, explained $4 \%$ of the variance in depressed mood (Thune-Bolye, Stygall, Keshtgar, Davidson, \& Newman, 2012). They also found that slightly over half of the participants experienced spiritual struggle, and noted the significance of this finding in the European context, which is more secularized than in the US, which is where the majority of previous studies have been 
carried out (Thune-Bolye, Stygall, Keshtgar, Davidson, \& Newman, 2011). Moreover, they found that the use of certain forms of negative religious coping varied over the 12-month span of the study, with women reporting significantly higher levels of feeling punished or abandoned by God at the time of surgical intervention and at 12-months post-operatively than at 3-months (Thune-Bolye, et al., 2011). Ramirez and colleagues (2012) found that spiritual struggle was independently related to increased psychological distress and decreased health-related quality of life in a sample of 170 adults with end-stage renal disease. Two studies have recently explored spiritual struggle and psychiatric diseases. In a study of 241 college undergraduates, spiritual struggle partially mediated the relationship between trauma and post-traumatic stress disorder symptoms (Wortmann, et al., 2011). Webb and colleagues reported that increased spiritual struggle predicted poorer recovery from mental diseases in a sample of 81 adults, and that this was mediated by religious support (Webb, Charbonneau, McCann, \& Gayle, 2011).

Studies of the harmful physical effects of spiritual struggle have also been reported. For example, among 96 medical rehabilitation patients, in models adjusted for demographic factors, depression and social support, higher levels of spiritual struggle at baseline were associated with poorer recovery of independent ambulation at 4 month follow-up (Fitchett, et al., 1999). Among 239 older adult medical patients, those with any spiritual struggle had increased functional limitations, increased levels of depressive symptoms, and poorer quality of life in models adjusted for demographic factors, compared to those with no evidence of spiritual struggle at baseline or 2 year follow-up (Pargament, et al., 2004). Two year follow up of this sample for mortality found that higher levels of spiritual struggle were associated with an increased risk of mortality $(\mathrm{OR}=1.06,95 \% \mathrm{CI} 1.01,1.11)$ in models that adjusted for demographic, psychological, and medical factors (Pargament, Koenig, et al., 2001a). Reports of the prevalence of spiritual struggle vary from $7 \%$ to $50 \%$ across various studies with multiple populations and may be related to clinical and situational factors, cultural context, as well as the criteria employed for determining its presence (Fitchett, et al., 2004; Fitchett \& Risk, 2009; Johnson \& Hayes, 2003; Thune-Bolye, et al., 2011). Pargament (2008) describes spiritual struggle as a "fork in the road" which can lead a person either towards growth or chronic struggle (Pargament, 2008). For example, increased stress-related growth was positively associated with higher levels of spiritual struggle among persons who were members of congregations located near the bombing in Oklahoma City (Pargament, Smith, Koenig, \& Perez, 1998). Spiritual struggles associated with a positive HIV diagnosis have been associated with positive outcomes as well (Ironson, Stuetzle, \& Fletcher, 2006). Positive outcomes, including increased self-reliance, spirituality and closeness to God, were associated with experiencing a sacred violation in a romantic relationship (Magyar, Pargament, \& Mahoney, 2000).

Empirical information about the experience of spiritual struggle due to the illness of a child is limited. Evidence of spiritual struggle was found in a small proportion of the prayers written in an open notebook in a pediatric hospital chapel (Grossoehme et al., 2011). In a study of parents of children who have autism, Tarakeshwar and Pargament (2001) found that $5-19 \%$ of their sample of 45 parents experienced at least one form of spiritual struggle. Based upon qualitative interviews with 15 parents of children diagnosed with cystic fibrosis in the previous twelve months, Grossoehme and colleagues (2010) found up to $33 \%$ of the 
parents reported spiritual struggles (Grossoehme et al., 2010). Additionally, mothers of adolescents with sickle cell disease reported negative religious coping styles associated with potential spiritual struggle in $10-12 \%$ of the sample ( $N=26$; Cotton et al., 2009). Families may engage in styles of religious coping associated with poorer health outcomes when their child or their family functioning does not fulfill their normative expectations of a healthy family (Dumas \& Nissley-Tsiopinis, 2006).

Fitchett and colleagues (2000) previously reported on the pattern of patients' self-referrals to chaplaincy, and that those who requested a chaplain's visit were those with higher spiritual resources and fewer needs (Fitchett, Meyer, \& Burton, 2000). Patients with higher spiritual needs were less likely to request a chaplain. Since chaplains are usually a limited resource in health care institutions and tend to respond to identified needs, it is likely that persons with greater spiritual needs or spiritual struggle go unidentified and therefore are not assisted by chaplains.

The growing evidence of the harmful effects of spiritual struggle, and the evidence suggesting those with greater spiritual needs are not more likely to self-refer for spiritual care, points to the need for a method for screening for spiritual struggle in clinical contexts. Having a spiritual struggle screening protocol could increase chaplains' efficiency and productivity by creating a reliable means of identifying individuals with potential spiritual struggle.

\section{Development and Initial Testing of the Rush Protocol}

The Rush Protocol (RP) was developed to fill the need for a method to screen patients in a variety of healthcare contexts for potential religious and spiritual struggle (Fitchett \& Risk, 2009). The development of the protocol was guided by the assumption that it would be employed by non-chaplain healthcare professionals. These professionals could use it in the context of initial assessment or intake interviews to identify patients who may be experiencing religious or spiritual struggle. Persons who may be experiencing religious or spiritual struggle would then be referred to a professional chaplain for further assessment, and where indicated, spiritual care.

The development of the protocol was also guided by three additional assumptions. First, it should be simple and require minimal training to be used effectively. Second, it should be brief so that busy healthcare professionals are willing to include it in their assessments. Finally, it was assumed that patients who were experiencing religious or spiritual struggle, for example feeling angry with God, would not necessarily be comfortable disclosing this information in the context of an initial assessment with a health professional they don't know well; thus, the screening questions should be relatively neutral (Taylor, Outlaw, Bernardo, \& Roy, 1999).

As can be seen in Figure 1, the RP has two pathways for identifying patients with potential religious or spiritual struggle. Both pathways begin with the same question, "Is religion or spirituality important to you as you cope with your illness?" Those who answer, "Yes," are in the first pathway for which the follow-up question is, "How much strength and comfort do you get from your religion/spirituality right now?" The response choices for this question 
in the revised version of the protocol are "All that I need," "Less than I need," or "None at all." Responses of "Less than I need," or "None at all" are considered indicators of potential religious or spiritual struggle. The follow-up question in this pathway is based on evidence that high levels of salience or involvement in religion or spirituality do not guarantee religious and spiritual comfort or provide immunity from religious and spiritual struggles (Fitchett, et al., 2004).

The second pathway in the protocol is for patients who respond that religion or spirituality is not important in coping with their illness. It is designed to determine if current disinterest in religion or spirituality is a longstanding, emotionally neutral pattern or whether it may be an indicator of unresolved doubt, disappointment or painful experiences with religious or spiritual beliefs, organizations, or representatives. The follow-up question in this pathway is, "Has there ever been a time when religion or spirituality was important to you?" A response that "Yes," there was a time when religion or spirituality was important is considered an indicator of potential religious or spiritual struggle. The questions in this pathway are based on evidence that some people who discontinue religious involvement have had disappointing or harmful experiences with religious leaders or other forms of religious or spiritual struggle (Zinnbauer et al., 2000).

The inclusion of this pathway was also informed by the increased risk of post-operative mortality for CABG patients who reported they were getting no strength and comfort from religion (Oxman, Freeman, \& Manheimer, 1995). These results raised the question of whether there were two subgroups of patients among those who responded "None" to this question. The first was a group, perhaps small, who had no interest in religiousness and whose disinterest had little impact on their post-surgical outcome. The second group were potentially experiencing harmful religious struggle but the question only permitted them to indicate that they were not receiving any strength and comfort from religion. The study did not include a way for them to signal their painful experiences with religion (Oxman, et al., 1995).

If a patient provides responses that indicate potential religious or spiritual struggle through either pathway, the patient should be referred to a chaplain for more in-depth spiritual assessment to determine if religious or spiritual struggle is present and, if indicated, to provide appropriate spiritual care. Where there are no indications of religious or spiritual struggle, as seen in Figure 1, additional questions about whether the patient wishes to have a visit from a chaplain can be added. Referral to a chaplain for routine care should be made for those patients who express an interest in a chaplain visit. When the RP is used with these additional questions about a chaplain visit, the identification of three groups of patients is possible: those with potential religious and spiritual struggle who may benefit from spiritual care but are unlikely to request it, those who appear not to be experiencing any religious or spiritual struggle but who would appreciate a chaplain's visit and who may be dissatisfied with their care if they do not receive one (Astrow, Wexler, Texeira, He, \& Sulmasy, 2007; Williams, Meltzer, Arora, Chung, \& Curlin, 2011), and patients who do not appear to be experiencing religious or spiritual struggle and who do not wish to see a chaplain. Being able to identify which patients are in each of these groups can reduce the time chaplains 
spend in case finding and help them make more efficient and effective use of limited resources.

The initial testing of the RP focused on the feasibility of integrating the screening in routine care (Fitchett \& Risk, 2009). This testing was conducted with medical rehabilitation patients in three phases with different health professionals administering the RP in each phase. Each group of health professionals received training about the use of the RP. This training included information about the role of religion, spirituality and spiritual struggle in health, the importance of screening for spiritual struggle, how to administer the RP, and how to communicate the results of the RP to the unit chaplain. In Phase 1 patient care technicians or nursing assistants were responsible for the screening and successfully screened $49 \%$ of new admissions. In an effort to improve the rate of successful screening in Phase 2, the screening was conducted by medical residents who successfully screened $22 \%$ of new admissions. In Phase 3, staff in the Department of Behavioral Sciences (psychologists and psychology interns) saw all new medical rehabilitation admissions and they agreed to include the RP in their assessments. They successfully screened $79 \%$ of all new admissions.

Since the focus of the previous project was on testing the feasibility of the RP, the validity and reliability of the protocol was not examined. However, among the 173 patients who were screened with the RP in all three phases of the testing, 12 (7\%) were identified as potentially experiencing religious or spiritual struggle and were referred to a board certified staff chaplain for assessment. The chaplain's assessment confirmed religious or spiritual struggle in 11 of these 12 patients (92\%). If the chaplain assessment is taken as a gold standard, in this trial of the RP there were $92 \%$ true positives and $8 \%$ false positives. The chaplain did not visit all of the patients who screened negative for religious or spiritual struggle so no estimate of true and false negatives could be derived from the previous project (Fitchett \& Risk, 2009). Nevertheless, in visits with some of the newly admitted patients who were not identified as experiencing religious or spiritual struggle by the RP, the chaplain identified a number of individuals who were experiencing religious or spiritual struggle, suggesting that the RP had yielded some false negatives.

A broad estimate of the extent to which the use of the RP in this population successfully identified cases with potential religious or spiritual struggle can be made by comparing the prevalence of cases with potential religious or spiritual struggle identified by the RP (7\%) with estimates of religious and spiritual struggle in other studies. In a previous study of medical rehabilitation patients conducted on the same unit $12 \%$ were found to have high levels of religious and spiritual struggle (Fitchett, et al., 1999). In a group of medical in- and out-patients with diabetes, congestive heart failure, or cancer, $15 \%$ were found to have moderate or high levels of religious and spiritual struggle (Fitchett, et al., 2004). In a study of 239 older medical patients, $26 \%$ were found to have indications of any religious or spiritual struggle at both baseline and 2 years later (Pargament, et al., 2004). The higher proportion of cases in this study may be attributed to the different thresholds that were employed to identify religious and spiritual struggle (eg., any vs. moderate or high; (Pargament, et al., 2004). The low proportion of patients on the medical rehabilitation unit who screened positive for religious and spiritual struggle based on the RP may reflect, in 
part, the generally positive prognosis of some of the patients (e.g., joint replacement) treated in this context.

Since its development, the RP has been utilized for clinical and research purposes but published reports of these efforts are only beginning to appear. For example, chaplains at Maine Medical Center worked with nursing colleagues to introduce a revised version of the RP on their oncology unit (Blanchard, Dunlap, \& Fitchett, in press). Clinimetrics is the science of clinical measurement (Fava, Tomba, \& Sonino, 2012; Mokkink et al., 2010). Two reports provide some additional evidence of the clinimetric properties of the RP. The RP was incorporated in an electronic self-report of symptoms for use with oncology patients, the Electronic Self Report Assessment for Cancer (ESRA-C; (Berry et al., 2011). Among 178 blood and marrow transplant (BMT) patients who completed the ESRA-C at the Seattle Cancer Care Alliance, $18 \%$ were identified as potentially experiencing religious or spiritual struggle (King, Fitchett, \& Berry, 2012). In this sample, more recent diagnosis was associated with a positive screen for religious or spiritual struggle. Specifically, compared to those diagnosed more than two years ago, among those diagnosed in the past six months or less, the odds ratio for positive screening for spiritual struggle was $17.72(95 \% \mathrm{CI}=3.54$, $88.58, \mathrm{p}<.001)$. While there was a low level of depressive symptoms in the sample overall, those who screened positive for religious or spiritual struggle also had marginally higher levels of depressive symptoms ( $\mathrm{p}<0.10$ ). All of these patients were also evaluated by a social worker whose interview included inquiry about religious and spiritual concerns. The social workers' reports of these interviews were examined for indications of religious and spiritual struggle and none were noted. This may be due to the fact that the social workers' interviews included a general inquiry about religiousness and spirituality but nothing specific about spiritual struggle. A finding that suggests unless there is intentional screening, possible spiritual struggle may not be identified.

The RP was also used to screen for spiritual struggle in a study of 197 older adults with depression who were referred from primary care practices to an interdisciplinary team intervention for depression (Murphy, Fitchett, Brunner, \& Emery, 2012). In this sample 51\% screened positive for potential spiritual struggle. Hispanics were less likely than nonHispanic Caucasians to screen positive for spiritual struggle $(\mathrm{OR}=0.40,95 \% \mathrm{CI}=0.16$, $0.99)$. Age was also inversely associated with spiritual struggle ( $\mathrm{OR}=0.95,95 \% \mathrm{CI}=0.92$, 0.99). Gender, marital status, education, African-American race and number of chronic illnesses were not associated with spiritual struggle. While all of these patients had elevated levels of depressive symptoms, the convergent validity of the RP is suggested by the fact that positive screening for spiritual struggle was associated with higher levels of depressive symptoms $(t(195)=-2.841, \mathrm{p}=0.005)$, a difference that remained significant after adjustment for demographic and medical factors.

This limited body of evidence suggests the RP may be useful for screening for religious and spiritual struggle among diverse clinical populations. However, it also makes evident that additional testing of the clinimetric properties of the RP are needed. A key need is to compare results from the RP with another well-validated measure of religious and spiritual struggle. Comparisons of results from the RP with measures of related constructs, convergent validity, are also needed, as are studies of the RP with additional clinical 
samples where religious and spiritual struggle is of concern. The present study was designed to fill some of these gaps.

\section{Method}

\section{Participants and Procedure}

This study was approved by the Institutional Review Board, and carried out at a 475-bed academic pediatric hospital in the Midwestern United States. Participants were parents of children diagnosed with cystic fibrosis (CF) who were followed at the CF Center at this institution. The CF Center followed approximately 225 children from birth to 22 years old at the time of the study. This sample is comprised of a convenience sample of 22 parents (100\% acceptance rate) who were recruited in the context of a larger study of factors, including spiritual factors, affecting their adherence to their child's home treatment regimen. The larger study used a concurrent triangulation design, as described by Creswell (2009) which allowed participants the greatest flexibility in managing the time of their participation in the qualitative and quantitative arm of the study. Participants completed a telephone interview and a set of questionnaires. Telephone interviews are preferred over in-person interviews when sensitive topics, such as spirituality or treatment adherence are the focus, and have been shown to yield better data (Clark, Rogers, Armstrong, Rakowski, \& Kviz, 2008; Jaya, Hindin, \& Ahmed, 2008; Midanik, Greenfield, \& Rogers, 2001). Inclusion criteria were having a child aged three months to 13 years old who was diagnosed with $\mathrm{CF}$ and the ability to speak English. Half of the children were diagnosed by newborn screening (typically within 5 day of birth); of the remaining 50\%, six were diagnosed before age 1 year and five between 1 and 10 years of age. Interviews were completed between May and October, 2011. After completing informed consent, parents were provided with a URL address to enter their questionnaire data using REDCap Survey at their convenience. Mean elapsed time between the interview and questionnaire completion was 27 days, minimizing potential administration effects. Questionnaire design followed the model of Alreck and Settle (1995) to minimize administration effects within the survey itself (Alreck \& Settle, 1995). Demographic questions which applied to all were first, followed by what clinical experience suggested was an approximately increasing order of emotionality: general coping, religious coping, congregational support, body sanctification, depressive symptoms, marital adjustment, and treatment adherence. Study data were collected and managed using REDCap, which is a secure, web-based application designed to support data capture for research studies (Harris et al., 2009).

\section{Measures}

Spiritual struggle-The screening questions for spiritual struggle proposed by Fitchett and Risk (2009) were administered orally by the first author during the telephone interview with the following modification: the follow-up question, "Would you like a visit from a chaplain?" was not asked of participants since this was a research interview and no clinical follow-up was planned. Deleting this question, which is to be asked only when the screening suggests a negative finding (no struggle), was judged unlikely to alter the tone of the screening. As described elsewhere, persons most likely to experience spiritual struggle are least likely to request a chaplain's visit (Fitchett, et al., 2000). In addition, participants were 
acquainted with the first author through his clinical role as chaplain with the cystic fibrosis team, and they would expect contact from the chaplain as part of their clinical care.

Religious coping-At this stage in the empirical literature there is no measure that can be considered the "gold standard" for measuring spiritual struggle. The RCOPE developed by Pargament and colleagues (Pargament, Koenig \& Perez, 2000) is the most comprehensive instrument, assessing 21 dimensions of religious and spiritual coping with a total of 105 items. However, because of its length it is not practical for use in many studies. Factor analysis indicated that the RCOPE items loaded on a positive and negative factor (Pargament, Feuille \& Burdzy, 2011). The 14-item Brief RCOPE was created by selecting items with high factor loadings that represented a variety of coping styles. Between 2005 and 2010 the Brief RCOPE was used in at least 30 studies and is the most commonly used measure of religious and spiritual coping (Pargament et al., 2011). Thus, the negative religious coping subscale of the Brief RCOPE is the best available measure to test the construct validity of the RP. Pargament and colleagues describe at least two studies which have sought to validate this scale in more diverse religious and cultural groups than the mainly Christian, Euro-American samples in which it was developed and most extensively used (Pargament, et al., 2011). Results were mixed; the positive religious coping items generally supported the validity of the positive subscale, and the negative subscale was either unreliable or was more correlated with anxiety and depression than with religious constructs. However, given the extremely rare incidence of cystic fibrosis outside of Caucasians (Wilfond \& Taussig, 1999), this was not judged to be a significant issue in the present study.

The Brief RCOPE has two subscales of 7 items each, covering positive and negative styles of religion coping. For example, a positive religious coping item is, "Looked for a stronger connection with God"; a negative religious coping items is, "Felt punished by God for my lack of devotion." Respondents answer how often they use each of the religious coping styles using a 4-point Likert-style scale ranging from 0 ("did not use") to 3 ("used a great deal"). Total scores for each subscale therefore range from 0 to 21 . This scale is wellestablished with good psychometric properties $(0.85<a<0.93)$. Given the sample size and the relatively low incidence of negative spiritual coping styles, we followed an approach similar to that described by Fitchett and colleagues to further categorize the responses (Fitchett, et al., 2004). Each of the item scores were dichotomized, with scores of 0 or 1 recoded to "0" and scores of 2 or 3 recoded to " 3 ". This reflects a response of "not used" or "used" each style. To determine the use of negative religious coping, we created a dichotomous variable which was given a value of " 1 " if any one (or more) of the seven negative spiritual coping styles had a value of "3;" otherwise it was given the value of " 0 ."

Depressive symptoms-Depressive symptomatology was measured using the Center for Epidemiologic Studies Depression Scale (CES-D; (Radloff, 1977). This questionnaire is comprised of 20 items (depressive symptoms); responses indicate the frequency with which each symptom has been experienced in the past week, ranging from 0 ("Rarely or none of the time (less than 1 day)") to 3 ("Most or all of the time (5-7 days)"). The range of possible scores is $0-60$; a score of 16 or greater may be taken to indicate symptomology of clinical 
significance in the United States. This scale is commonly used and has published values for Cronbach's alpha ranging from 0.82 to 0.95 (Garrison, Addy, Jackson, McKeown, \& Waller, 1991; Hooker, Manahan, Shifren, \& Hutchinson, 1992).

Disease severity-Disease severity was operationalized by using the number of pulmonary exacerbations requiring the use of intravenous antibiotic therapy during the twelve month period prior to the interview. Pulmonary exacerbations are a common measure of disease severity in pediatrics, where direct measures of pulmonary function, such as forced expiratory volume are not possible due to the age of the children (Britto et al., 2002). This data was obtained by chart review.

\section{Analysis}

Descriptive statistics for each questionnaire were obtained. Sensitivity and specificity for the RP were also determined, using the negative religious coping subscale of the Brief RCOPE as the standard for comparison. All analyses were carried out using SPSS 20.0

\section{Results}

A total of twenty two parents were interviewed; this sample represents $100 \%$ of the eligible parents approached for participation. Demographic and clinical data for the participants and their children are presented in Table 1. Participants' religious affiliations approximate that of the eligible population (that is, the particular CF Center from which they were drawn), based on comparison of percentages obtained by chart review. The mean score for depressive symptoms (16.6) is at the cutoff value of 16 for symptomatology of clinical significance. The mean score for positive religious coping was moderate; and the mean negative religious coping score was relatively low. The percentage of participants determined by the dichotomized negative RCOPE score to have potential spiritual struggle was $32 \%$. The children of the parents who participated had a generally mild disease severity; $50 \%$ had one or more $\mathrm{CF}$ exacerbations in the past year.

Using the RP, $18 \%$ of the parents screened positive for possible spiritual struggle. There was a strong correlation between negative religious coping score and CES-D (depressive symptomatology) score (Spearman's rho $=0.640 ; \mathrm{p}=0.002$ ). We compared the mean CES-D scores between those screened by the RP as negative $(\mathrm{M}=14.6 ; \mathrm{SD}=18.3)$ or positive $(\mathrm{M}=28.7, \mathrm{SD}=18.3)$ for spiritual struggle and found a significant difference $(t(19)=2.24$, $\mathrm{p}=0.038)$. This corresponds to a medium effect size ( 0.44 ; Cohen's $d=0.98)$.

Figure 2 shows the parents' responses to the RP questions. From the figure it can be seen that the vast majority of the parents (91\%) reported that religion and spirituality was important to them in coping with their child's illness. However, among those for whom religion and spirituality was important, $2(9 \%)$ parents reported not receiving all the strength and comfort they needed, the first protocol pathway indicating potential spiritual struggle. Figure 2 also shows that 2 (9\%) parents who indicated that religion and spirituality was not important now indicated that it had been important in the past. That is, they screened positive for potential spiritual struggle on the protocol's second pathway. 
Table 2 shows the sensitivity and specificity of the RP using the negative religious coping subscale of the Brief RCOPE as the standard. There were 2 "true positives" and 13 "true negatives" out of the 22 participants. This yields a sensitivity (TP/[TP+FN]) of $29 \%$ and specificity (TN/[TN+FP]) of $87 \%$. A comparison among all four groups, true and false positives and negatives, is presented in Table 3. Participants who were true positives had higher mean scores of depressive symptomatology than any of the other three groups. The relationship between disease severity and positive screener results was non-significant $\left(\mathrm{X}^{2}(4)=7.12, \mathrm{p}=0.13\right)$.

\section{Discussion}

What is the prevalence of spiritual struggle among parents of children diagnosed with CF? Using the RP we found that $18 \%$ of the parents screened positive for possible spiritual struggle. Based on scores on the negative religious coping subscale of the Brief RCOPE, one of the most commonly used measures of spiritual struggle, $32 \%$ of the parents had scores $(\geq 2)$ that might indicate spiritual struggle. To put these prevalence estimates in perspective we can compare them with other studies of parents of children with CF and with other studies of caregivers as well as community samples. In a study of 15 parents of children with $\mathrm{CF}$, similar to those who participated in this study, $33 \%$ were found to have spiritual struggle (Grossoehme, Ragsdale, Wooldridge, Cotton, \& Seid, 2010). Spiritual struggle has also been reported for parents of children with autism (Tarakeshwar \& Pargament, 2001), sickle cell disease (Cotton et al., 2009) and other conditions (Dumas \& Nissley-Tsiopinis, 2006). There are also reports of spiritual struggle among caregivers of adults with conditions such as dementia (Herrara, Lee, Nanyonjo, Laufman, \& Torres-Vigil, 2009), cancer (Pearce, Singer, \& Prigerson, 2006), and patients in hospice (Mickley, Pargament, Brant, \& Hipp, 1998). For purposes of comparison, levels of spiritual struggle observed in the 1999 General Social Survey, a survey of a representative sample of the U.S. adult population, were quite low, 5.8\% reported feeling punished by God and 2.9\% reported feeling abandoned by God "quite a bit" or "a great deal" (Fetzer/National Institute on Aging, 1999). Based on these reports it appears that the RP may underestimate the proportion of individuals who may be experiencing spiritual struggle.

When results from the RP are compared with those based on negative RCOPE the sensitivity $(29 \%)$ is low while the specificity (89\%) is relatively good. The sensitivity of a screening instrument reflects its ability to correctly identify cases with the condition of interest (true positives). Specificity reflects its ability to correctly identify cases without the condition (true negatives). Several considerations should be kept in mind in interpreting these results. First, while it is one of the most commonly used measures of spiritual struggle, the negative religious coping subscale of the Brief RCOPE cannot be said to be a true "gold standard" for identifying harmful levels of spiritual struggle. One reason for this is because 5 of the 7 items in the measure focus on struggle with the Divine, which is only one type of spiritual struggle (Exline and Rose, 2005; Pargament et al., 2005). The other two types of spiritual struggle described by Pargament and colleagues (2005) are interpersonal (spiritual conflicts with other people or groups of people) and intrapersonal (doubts or questions about one's purpose, beliefs or values). 
Another reason the Brief RCOPE cannot be said to be a true "gold standard" is that, while there is evidence that even low average levels of negative religious coping are associated with worse emotional and physical outcomes in clinical samples, a cutoff for clinically significant negative religious coping scores has not been established. In contrast to the negative religious coping items, the RP does not explicitly address struggle with the Divine which may partially explain the false negative cases that we observed.

Research suggests that interpersonal religious and spiritual conflicts can cause permanent changes in religious and spiritual identity and practices (Zinnbauer et al., 2000). For example, among 157 older adults, $22 \%$ reported discontinuing worship attendance in midlife primarily due to interpersonal differences with the clergy, lay leaders, or fellow members of their congregation (George, Hays, Flint, \& Meador, 2004). While only one item in the negative RCOPE measures this type of spiritual struggle ("I wondered whether my church had abandoned me") pathway 2 of the RP may be more effective in identifying people who have disengaged from religious involvement in part due to such interpersonal conflicts. This difference may partially explain the false positive cases in this analysis. Other research reports higher levels of religious and spiritual struggle among those who report no religious affiliation, including some of those who describe themselves as atheists or agnostics (Exline, Park, Smyth, \& Carey, 2011; Exline, Yali \& Sanderson, 2000). For example, in a study of 244 bereaved adults, the 8 participants who described themselves as atheists had the highest scores on a measure of anger with God (Exline, Park, Smyth, \& Carey, 2011). Persons like this will likely answer "No" to the initial question in the RP and therefore would not be included in Pathway 1. Further research is needed to determine if pathway 2 of the RP is effective in identifying persons with this type of religious or spiritual struggle.

The small size of the sample in the present study does not permit a rigorous analysis of the differences among parents who were categorized in Table 2 as true and false positives and true and false negatives. Nonetheless, the data in Table 3 permits some tentative observations about the validity of the RP. Specifically, parents who were identified as true positives, that is as having spiritual struggle on both the RP and the negative RCOPE, had the highest average score for depressive symptoms. This is consistent with reports of a positive association between spiritual struggle and depression in other clinical samples (Fitchett, et al., 2004; Herbert, Zdaniuk, Schulz, \& Scheier, 2009; Pearce, et al., 2006; Sherman, Plante, Simonton, Latif, \& Anaissie, 2009).

\section{Limitations and Clinical Implications}

This study has several limitations. The sample size is quite small, and the small number of persons screened as positive suggests caution about interpreting this as having clinical significance (although it may). In addition, the children of parents in this sample had relatively mild disease; a larger sample size may have revealed an association between the presence of spiritual struggle for parents and their child's health status. Since these data were gathered in the context of a larger study with a different focus, the measures available to test the clinimetric properties (e.g., convergent validity) of the RP were limited. Nonetheless, important conclusions can still be drawn. We present the first independent report of the use of the RP spiritual struggle screener and demonstrate that parents of 
children with CF find it acceptable to answer its questions, and that it is feasible to administer orally. In addition, although the sensitivity of the RP in this sample was low, the specificity was reasonably high.

Future work on the RP is part of a wider body of clinimetric research needed for all of the procedures and instruments currently being used for spiritual screening, spiritual historytaking, and spiritual assessment (Fitchett, 2012). Future research with the RP should be undertaken with larger samples of parents of children with CF in order to extend the preliminary results presented here. Work with other clinical samples is also needed to assess whether the RP has wider feasibility, validity and reliability. Future work should separately examine the validity and reliability of each of the two pathways in the Protocol. Future work should also employ a true gold standard to determine whether spiritual struggle is indeed present, such as a spiritual assessment conducted by a professional chaplain.

Spiritual assessments, unlike spiritual screening or spiritual history tools, are the technical name given to, “.... an in-depth, on-going process of evaluating the spiritual needs and resources of persons for whom..." chaplains care (Fitchett, 2012, p. 300). The modifiers "indepth" and "on-going process"are significant: assessments are not a set of standard questions to develop cross-sectional data, but instead are interpretive frameworks for listening longitudinally to a person's story. Models for this are described elsewhere (Fitchett, 2012). This interpretive work is basic to health care chaplaincy, and chaplains' unique training is based on actively listening to, and reflecting, the spiritual meaning of events. While someone may indicate in a screening that their faith was more important to them in the past than it is now, this does not necessarily indicate the existence of "spiritual struggle," and only a deeper, narrative exploration of the change can determine whether or not such a struggle exists for that individual. Spiritual screening tools, such as the RP described here, as well as spiritual history tools (e.g., FICA;(Puchalski \& Romer, 2003) were developed to be used by clinicians who are not chaplains, and to determine whether or not a more in-depth spiritual assessment is indicated.

Responsiveness is the term used to describe whether a clinical instrument can detect change in a construct over time (Mokkink, et al., 2010). Some longitudinal studies have described the trajectory of spiritual struggle for different clinical groups (Gall, Kristjansson, Charbonneau, \& Florack, 2008; Pargament, et al., 2004; Sherman, et al., 2009). Future research on the RP should also determine if it is useful in detecting important changes in spiritual struggle.

An assumption that informed the development of the RP was that patients would be uncomfortable if unfamiliar healthcare professionals asked sensitive questions about their religious and spiritual beliefs and experiences (e.g., about anger with God, or about harsh or abusive treatment from religious authorities) in the context of initial assessments. This assumption needs to be tested, and would be relatively easy to do, by asking patients if more explicit questions would make them uncomfortable and providing examples of such questions. Evidence has shown that patients are not uncomfortable answering sensitive questions in computerized self-reports (Robling et al., 2010). Thus, future research should explore whether this is also true for topics like spiritual struggle. It would aid the integration 
of spiritual care immensely if health professionals were able to accurately screen for spiritual struggle as part of the electronic self-reports that are increasingly being implemented in outpatient settings where patients with serious illness and those receiving palliative care are treated.

This study has the following clinical implications. First, when someone has been identified by the RP as having screened positive for potential spiritual struggle, such individuals should be referred to the chaplain for assessment. It is not appropriate to ask such individuals if they want to speak a chaplain; it has been shown that persons with the greatest spiritual needs and fewest spiritual resources are least likely to request a chaplain (Fitchett, et al., 2000). Identifying a potential risk factor for poorer health outcomes, and then not taking steps to confirm or deny the presence of the actual risk, is a questionable ethical stance. By performing a screening, the health care professional assumes the same duty of care based on the outcome of the screening, as they would if the patient themselves had come to the professional for help with that issue (Edwards \& Hall, 1992). By analogy, a person screened for colorectal cancer is referred to a specialist for confirmation of the diagnosis - not offered the opportunity to speak with an oncologist. A follow-up spiritual assessment by a clinical chaplain is the gold-standard because of the chaplain's specialized training not only in the content area but in non-judgmental, active listening skills. Provision of this follow-up assessment is the next ethical level of providing care.

The best person to administer the RP will depend on practices in each clinical context. The key point is well-stated in the recommendation from the Palliative Care Consensus Conference, "All patients should receive a simple and time-efficient spiritual screening at the point of entry into the health care system and appropriate referrals as needed" (Puchalski et al., 2009, p.893). The initial RP study found that psychologists were effective in administering the Protocol (Fitchett \& Risk, 2009). In that study medical residents had poor rates of screening, but other studies have shown that with proper training physicians can effectively inquire about patient's religious and spiritual needs and resources (Kristeller, Rhodes, Cripe, \& Sheets, 2005), as can nurses (King, et al., 2012) and social workers (Hodge, 2005).

The body of evidence describing the harmful effects of spiritual struggle continues to grow. This evidence comes from studies of adult patients with serious illness or chronic illness (Cotton, Tsevat, et al., 2006; Fitchett, et al., 2004; Ramirez et al., 2012; Thune-Bolye, et al., 2012) as well as children and adolescents (Cotton et al., in press; Pendleton, et al., 2002) and from studies of parents and other caregivers (Daniel H. Grossoehme, et al., 2010; Pearce, et al., 2006; Tarakeshwar \& Pargament, 2001). These harmful effects include poorer quality of life and increased emotional distress (Herbert, et al., 2009; Sherman, et al., 2009), poorer recovery (Fitchett, et al., 1999), increased hospitalization (Park, Wortmann, \& Edmondson, 2011), decreased adherence to recommended treatment (Park, Moehl, Fenster, Suresh, \& Bliss, 2008) and increased risk of mortality (K. I. Pargament, H.G. Koenig, N. Tarakeshwar, $\& \mathrm{~J}$. Hahn, 2001b). In light of this evidence there is a clear need for a simple and timeefficient method of screening for spiritual struggle. Among the parents of children with CF interviewed in this study, the RP was a feasible and acceptable method of screening for spiritual struggle. While further research is needed, especially to improve its sensitivity, the 
$\mathrm{RP}$ is one method that should be considered by clinicians when screening for spiritual struggle..

\section{Acknowledgments}

This study was partially supported by grant NIH/NICD K23HD062642 (PI: Grossoehme), NIH/NCRR UL-1RR026314-01 (REDCap).

\section{References}

Ai AL, Pargament KI, Kronfol Z, Tice TN, Appel H. Pathways to postoperative hostility in cardiac patients: mediation of coping, spiritual struggle and Interleukin-6. J Health Psychol. 2010; 15:186195. [PubMed: 20207662]

Alreck, PL.; Settle, RB. The survey research handbook. 2nd ed.. Chicago: Irwin Professional Publishing; 1995.

Ano GG, Vasconcelles EB. Religious coping and psychological adjustment to stress: a meta-analysis. J Clin Psychol. 2005; 61(4):461-480. [PubMed: 15503316]

Astrow AB, Wexler A, Texeira K, He MK, Sulmasy DP. Is failure to meet spiritual needs assocaited with cancer patients' perceptions of quality of care and their satisfaction with care? J Clin Oncol. 2007; 25(36):5753-5757. [PubMed: 18089871]

Berman E, Merz JF, Rudnick M, Snyder RW, Rogers KK, Lee J, Lipschutz JH. Religiosity in a hemodialysis population and its relationship to satisfaction with medical care, satisfaction with life, and adherence. Am J Kidney Dis. 2004; 44(3):488-497. doi: S0272638604008182 [pii]. [PubMed: 15332222]

Berry DL, Blumenstein BA, Halpenny B, Woplin S, Fann J, Austin-Seymour M, McCorkle R. Enhancing patient-provider communication with the electronic self-report assessment for cancer: a randomized trial. J Clin Oncol. 2011; 29:1029-1035. [PubMed: 21282548]

Blanchard JH, Dunlap DA, Fitchett G. Screening for spriitual distress in the inpatient: a quality improvement initiative. Journal of Nursing Management. (in press).

Britto MT, Kotagal UR, Hornung RW, Atherton HD, Tsevat J, Wilmott RW. Impact of recent pulmonary exacerbations on quality of life in patients with cystic fibrosis. Chest. 2002; 121:64-72. [PubMed: 11796433]

Chida Y, Steptoe A, Powell LH. Religiosity/spirituality and mortality. A systematic quantitative review. Psychother Psychosom. 2009; 78(2):81-90. doi: 000190791 [pii] 10.1159/000190791. [PubMed: 19142047]

Clark MA, Rogers ML, Armstrong GF, Rakowski W, Kviz FJ. Differential response effects of data collection mode in a cancer screening study of unmarried women ages 40-75 years: a randomized trial. MBC Med Res Methods. 2008; 8(10)

Cotton S, Grossoehme DH, Rosenthal SL, McGrady ME, Roberts YH, Hines J, Tsevat J. Religious/ Spiritual coping in adolescents with sickle cell disease: a pilot study. J Pediatr Hematol Oncol. 2009; 31(5):313-318. 00043426-200905000-00002 [pii]. [PubMed: 19415008]

Cotton S, Pargament KI, Grossoehme DH, McGrady ME, Luberto C, Fitchett G. Spiritual struggles, health-related quality of life, and mental health outcomes in urban adolescents with asthma. RSSSR. 24 (in press).

Cotton S, Puchalski CM, Sherman SN, Mrus JM, Peterman AH, Feinberg J, Tsevat J. Spirituality and religion in patients with HIV/AIDS. J Gen Intern Med. 2006; 21(Suppl 5):S5-S13. doi: JGI642 [pii] 10.1111/j.1525-1497.2006.00642.x. [PubMed: 17083501]

Cotton S, Tsevat J, Szaflarski M, Kudel I, Sherman SN, Feinberg J, Holmes WC. Changes in religiousness and spirituality attributed to HIV/AIDS: are there sex and race differences? J Gen Intern Med. 2006; 21(Suppl 5):S14-S20. doi: JGI641 [pii] 10.1111/j.1525-1497.2006.00641.x. [PubMed: 17083495]

Cotton S, Weekes J, McGrady ME, Rosenthal SL, Yi MS, Pargament KI, Tsevat J. Spirituality and religiosity in urban adolescents with asthma. J Relig Health. 2010 
Dumas JE, Nissley-Tsiopinis J. Parental global religiousness, sanctification of parenting, and positive and negative religious coping as predictors of parental and child functioning. International Journal for the Psychology of Religion. 2006; 16(4):289-310.

Edwards PJ, Hall DMB. Screening, ethics and the law. British Medical Journal. 1992; 305:267-287. [PubMed: 1392854]

Exline, JJ.; Rose, E. Religious and spiritual struggles. In: Paloutzian, RF.; Park, CL., editors. Handbook of the psychology of religion and health. New York, NY: Guillford Press; 2005. p. 315-330.

Fava GA, Tomba E, Sonino N. Clinimetrics: the science of clinical measurements. Int J Clin Pract. 2012; 66(1):11-15. [PubMed: 22171900]

Fetzer/National Institute on Aging, W. G.. Mulitdimensional measurement of religiousness/spirituality for use in health research: A report of the Fetzer/National Insitute on Aging Working Group. Kalamazoo, MI: Fetzer Institute; 1999.

Fitchett, G. Next steps for spiritual assessment in health care. In: Cobb, M.; Pulchalski, C.; Rumbold, B., editors. Oxford textbook of spirituality in healthcare. Oxford: Oxford University Press; 2012. p. 299-305.

Fitchett G, Meyer PM, Burton LA. Spiritual care in the hospital: who requests it? Who needs it? J Pastoral Care. 2000; 54(2):173-186. [PubMed: 11067526]

Fitchett G, Murphy PE, Kim J, Gibbons JL, Cameron JR, Davis JA. Religious struggle: prevalence, correlates and mental health risks in diabetic, congestive heart failure, and oncology patients. Int $\mathbf{J}$ Psychiatry Med. 2004; 34(2):179-196. [PubMed: 15387401]

Fitchett G, Risk JL. Screening for spiritual struggle. J Pastoral Care Counsel. 2009; 63(1-2) 4-1-12.

Fitchett G, Rybarczyk BD, DeMarco GA, Nicholas JJ. The role of religion in medical rehabilitation outcomes: a longitudinal study. Rehabilitation Psychology. 1999; 44(4):333-353.

Folkman S, Lazarus RS, Dunkel-Schetter C, DeLongis A, Gruen RJ. Dynamics of a stressful encounter: cognitive appraisal, coping, and encounter outcomes. Journal of Personality and Social Psychology. 1986; 50(5):992-1003. [PubMed: 3712234]

Gall TL, Kristjansson E, Charbonneau C, Florack P. A longitudinal study on the role of spirituality in response to the diagnosis and treatment of breast cancer. J Behav Med. 2008

Garrison CZ, Addy CL, Jackson KL, McKeown RE, Waller JL. The CES-D as a screen for depression and other psychiatric disorders in adolescents. Journal of the American Society of Child \& Adolescent Psychiatry. 1991; 30(4):636-641.

Grossoehme DH, Jacobson CJ, Cotton S, Ragsdale JR, VanDyke R, Seid M. Written prayers and religious coping in a paediatric hospital setting. Mental Health, Religion and Culture. 2011; 14(5): 423-432.

Grossoehme DH, Ragsdale J, Cotton S, Wooldridge JL, Grimes L, Seid M. Parents' religious coping styles in the first year after their child's cystic fibrosis diagnosis. J Health Care Chaplain. 2010; 16(3-4):109-122. [PubMed: 20658425]

Grossoehme DH, Ragsdale JR, Wooldridge JL, Cotton S, Seid M. 'We can handle this': Parents' use of religion in the first year following their child's diagnosis with cystic fibrosis. Journal of Health Care Chaplaincy. 2010; 16(3):95-108. [PubMed: 20658424]

Harris PA, Taylor R, Thielke R, Payne J, Gonzalez N, Conde JG. Research electronic data capture (REDCap)--a metadata-driven methodology and workflow process for providing translational research informatics support. J Biomed Inform. 2009; 42(2):377-381. doi: S1532-0464(08)00122-6 [pii] 10.1016/j.jbi.2008.08.010. [PubMed: 18929686]

Herbert R, Zdaniuk B, Schulz R, Scheier M. Positive and negative religious coping and well-being in women with breast cancer. J Palliat Med. 2009; 12(6):537-545. [PubMed: 19508140]

Herrara AP, Lee JW, Nanyonjo RD, Laufman LE, Torres-Vigil I. Relgious coping and caregiver wellbeing in Mexican-American families. Aging and Mental Health. 2009; 13:84-91. [PubMed: 19197693]

Hodge DR. Developing a spiritual assessment toolbox: a discussion of the strengths and limitations of five different assessment methods. Health and Social work. 2005; 30(4):314-323. [PubMed: 16323723] 
Hooker K, Manahan D, Shifren K, Hutchinson C. Mental and physical health of spouse-caregivers: The role of personality. Pyschology and aging. 1992; 7(3):367.

Ironson G, Stuetzle R, Fletcher MA. An increase in religiousness/spirituality occurs after HIV diagnosis and predicts slower disease progression over 4 years in people with HIV. J Gen Intern Med. 2006; 21(Suppl 5):S62-S68. [PubMed: 17083503]

Jaya J, Hindin MJ, Ahmed S. Differences in young people's reports of sexual behaviors according to interview methodology: a randomized trial in India. Am J Public Health. 2008; 98(1):169-174. [PubMed: 18160677]

Johnson CV, Hayes JA. Troubled spirits: prevalance and predictors of religious and spiritual concerns among university studnets and counseling center clients. Journal of Counseling Psychology. 2003; 50(4):409-419.

King SDW, Fitchett G, Berry DL. Screening for religious/spiritual struggle in blood and marrow transplant patients. Supportive Care in Cancer. 2012

Koenig, HG.; King, D.; Carson, VB., editors. Handbook of Religion and Health. New York, NY: Oxford University Press; 2012.

Koenig HG, Pargament KI, Nielsen J. Religious coping and health status in medically ill hospitalized older adults. J Nerv Ment Dis. 1998; 186(9):513-521. [PubMed: 9741556]

Kristeller JL, Rhodes M, Cripe LD, Sheets V. Oncologist assisted spiritual intervention study (OASIS): patient acceptibiity and initial evidence of effects. Int J Psychiatry Med. 2005; 35(4): 329-347. [PubMed: 16673834]

Magyar, GM.; Pargament, KI.; Mahoney, AA. Violating the sacred: a study of desecration among college students. Paper presented at the 108th Annual Convention of the American Psychological Assocation; Washington, D.C.. 2000.

Mickley JR, Pargament KI, Brant CR, Hipp KM. God and the search for meaning among hospice caregivers. Hosp J. 1998; 13(4):1-17. [PubMed: 9883124]

Midanik LT, Greenfield TK, Rogers JD. Reports of alcohol-related harm: telephone versus face-toface interviews. J Stud Alcohol. 2001; 62(1):74-78. [PubMed: 11271967]

Mokkink LB, Terwee CB, Patrick DL, Alonso J, Stratford PW, Knol DL, deVet HC. The COSMIN study reached international consensus on taxonomy, terminology, and defintiions of measurement properties for health-related patient-reported outcomes. J Clin Epidemiol. 2010; 63(7):737-745. [PubMed: 20494804]

Murphy, P.; Fitchett, G.; Brunner, J.; Emery, E. Religious/spiritual struggle: prevalence and correlates among older adults with depression in the BRIGHTEN Program. Paper presented at the 2012 Gerontological Society of America; San Diego, CA. 2012.

Oxman TE, Freeman DH, Manheimer ED. Lack of social participation or religious strength and comfort as risk factors for death after cardiac surgery in the elderly. Psychosomatic Medicine. 1995; 57:5-15. [PubMed: 7732159]

Pargament, KI. Psychology of religious coping. New York: Guilford Press; 1997.

Pargament, KI. Religious struggles: a fork in the road to growth or decline. Paper presented at the Spirituality, Health, and Human Flourishing: Meaning? Measurement? Implications?; Durham, North Carolina. 2008.

Pargament KI, Ellison CG, Tarakeshwar N, Wulff KM. Religious coping among the religious: the relationship between religious coping and well-being in a national sample of Presbytrian clergy, elders, and members. Journal for the Scientific Study of Religion. 2001; 40:597-613.

Pargament KI, Feuille M, Burdzy D. The Brief RCOPE: Current psychometric status of a short measure of religious coping. Religions. 2011; 2:51-76.

Pargament KI, Koenig HG, Perez LM. The many methods of religious coping: development and initial validation of the RCOPE. J Clin Psychol. 2000; 56(4):519-543. [PubMed: 10775045]

Pargament KI, Koenig HG, Tarakeshwar N, Hahn J. Religious struggle as a predictor of mortality among medically ill elderly patients: a 2-year longitudinal study. Arch Intern Med. 2001a; 161(15):1881-1885. [PubMed: 11493130]

Pargament KI, Koenig HG, Tarakeshwar N, Hahn J. Religious struggle as a predictor of mortality among medically ill elderly patients: a two-year longitudinal study. Archives of Internal Medicine. 2001b; 161:1881-1885. [PubMed: 11493130] 
Pargament KI, Koenig HG, Tarakeshwar N, Hahn J. Religious coping methods as predictors of psychological, physical and spiritual outcomes among medically ill elderly patients: a two-year longitudinal study. J Health Psychol. 2004; 9(6):713-730. 9/6/713 [pii]. [PubMed: 15367751]

Pargament, KI.; Murray-Swank, N.; Magyar-Russell, GM.; Ano, G. Spiritual struggle: a phenomenon of interest to psychology and religion. In: Miller, WR.; H, D., editors. Judeo-Christian perspectives on psychology: human nature, motivation and change. Washington, D.C.: APA Pres; 2005. p. 245-268.

Pargament KI, Smith BW, Koenig HG, Perez L. Patterns of positive and negative relgiious coping with major life stressors. Journal for the Scientific Study of Religion. 1998; 37(4):710-724.

Park CL, Moehl B, Fenster JR, Suresh DP, Bliss D. Religiousness and treatment adherence in congestive heart failure patients. Journal of Religion, Spirituality \& Aging. 2008; 20(4):249-266.

Park CL, Wortmann JH, Edmondson D. Religious struggle as a predictor of subseqeunt mental and physical well-being in advanced heart failure patients. Journal of Behavioral Medicine. 2011; 34(6):426-436. [PubMed: 21279733]

Pearce MJ, Singer JL, Prigerson HG. Religious coping among caregivers of terminally ill cancer patients. Journal of Health Psychology. 2006; 11(5):743-759. [PubMed: 16908470]

Pendleton SM, Cavalli KS, Pargament KI, Nasr SZ. Religious/spiritual coping in childhood cystic fibrosis: a qualitative study. Pediatrics. 2002; 109(E8)

Puchalski CM, Ferrell B, Virani R, Otis-Green S, Baird P, Bull J, Sulmasy DP. Improving the quality of spriutal care as a dimension of palliative care: the report of the Consensus Conference. J Palliat Med. 2009; 21(10):885-904. [PubMed: 19807235]

Puchalski CM, Romer AL. Take a spiritual history allows clinicians to understand patients more fully. J Palliat Med. 2003; 3(1):129-137. [PubMed: 15859737]

Radloff LS. The CES-D Scale: a self-report depression scale for research in the general population. Applied Psychological Measurement. 1977; 1(3):385-401.

Ramirez SP, Macedo DS, Sales PMg, Figueiredo SM, Daher EF, Araujo SM, Carvalho AF. The relationship between religiosu coping, psychological distress and quality of life in hemodialysis patients. Journal of Psychosomatic Research. 2012; 72:129-135. [PubMed: 22281454]

Robling MR, Ingledew DK, Greene G, Sayers A, Shaw C, Sander L, Hood K. Applying an extended theoretical framework for data collection mode to health services research. BMC Health Serv Res. 2010; 10:180. [PubMed: 20576131]

Sherman AC, Plante TG, Simonton S, Latif U, Anaissie EJ. Prospective study of religious coping among patients undergoing autologous stem cell transplantation. Journal of Behavoral Health. 2009; 32:118-128.

Sherman AC, Simonton S, Latif U, Spohn R, Tricot G. Religious struggle and religious comfort in repsonse to illness: Health outcomes among stem cell transplant patients. J Behav Med. 2005; 28(4):359-367. [PubMed: 16049629]

Tarakeshwar N, Pargament KI. Religious coping in families with autism. Focus on Autism and other Developmental Delays. 2001; 16:247-260.

Taylor EJ, Outlaw FH, Bernardo TR, Roy A. Spiritual conflects associated with praying about cancer. Psycho-Oncology. 1999; 8:386-394. [PubMed: 10559798]

Thune-Bolye IC, Stygall J, Keshtgar MRS, Davidson TI, Newman SP. Religious coping strategies in patients diagnosed with breast cancer in the UK. Psycho-Oncology. 2011; 20:771-782. [PubMed: 20878874]

Thune-Bolye IC, Stygall J, Keshtgar MRS, Davidson TI, Newman SP. Religious/spiritual coping resources adn their relationship with adjustment in patients newly diagnosed with breast cancer in the UK. Psycho-Oncology. 2012

Webb M, Charbonneau AM, McCann RA, Gayle KR. Struggling and enduring with God, religious support and recovery from severe mental illness. Journal of Clinical Psychology. 2011; 67(12): 1161-1176. [PubMed: 22072528]

Wilfond, BS.; Taussig, LM. Cystic fibrosis: general overview. In: Taussig, LM.; Landau, LI., editors. Pediatric Respiratory Medicine. St. Louis: Mosby; 1999. p. 982-990. 
Williams JA, Meltzer D, Arora V, Chung G, Curlin FA. Attention to inpatients' religions and spiritual concerns: predictors and association with patient satisfaction. J Gen Intern Med. 2011; 26(11): 1265-1271. [PubMed: 21720904]

Wortmann JH, Park CL, Edmondson D. Trauma and PTSD symptoms: does spiritual struggle mediate the link? Psychol Trauma. 2011; 3(4):442-452. [PubMed: 22308201]

Zinnbauer BJ, Pargament KI, Cole B, Rye MS, Butter EM, Belavich TG, Kardar JL. Religion and spirituality: unfuzzying the fuzzy. Journal for the Scientific Study of Religion. 2000; 36(4):549564. 


\section{Spiritual Struggle Screening Protocol}

1. Is religion or spirituality important to you as you cope with your illness?

2. How much strength/comfort do you get from your religion/ spirituality right now?

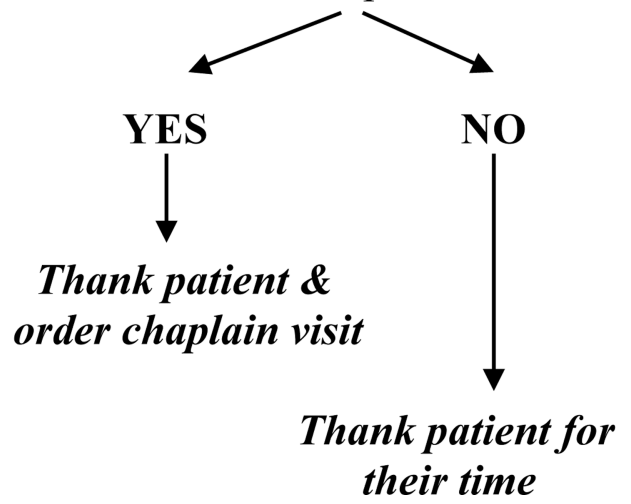

3. Would you like a visit from a chaplain?

A) all that I need

- For A, go to Question 3

B) somewhat less than I need

C) none at all

- For either B or C, thank patient \& order spiritual assessment

their time
NO

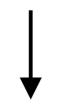

4. Has there ever been a time when religion/spirituality was important to you?
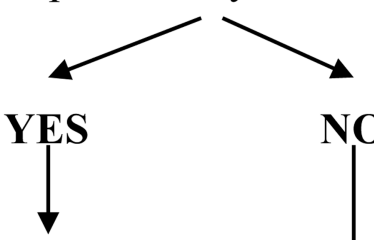

Thank patient \& order spiritual assessment
5. Would you like a visit from a chaplain?
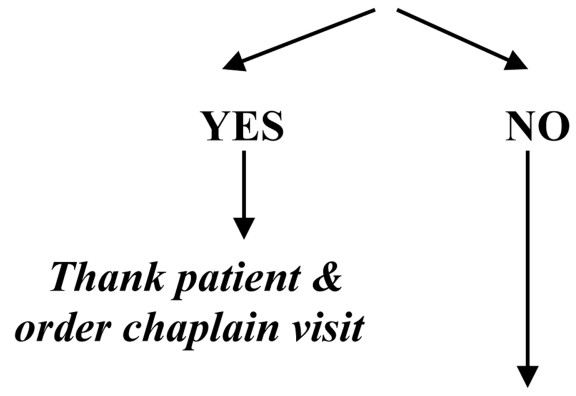

Thank patient for their time

Figure 1.

Rush Screening Protocol (RP) (Fitchett, G., \& Risk, J. 2009 Aug 19. Screening for Spiritual Struggle. Journal of Pastoral Care \& Counseling. [Online] 63:1,2.) 


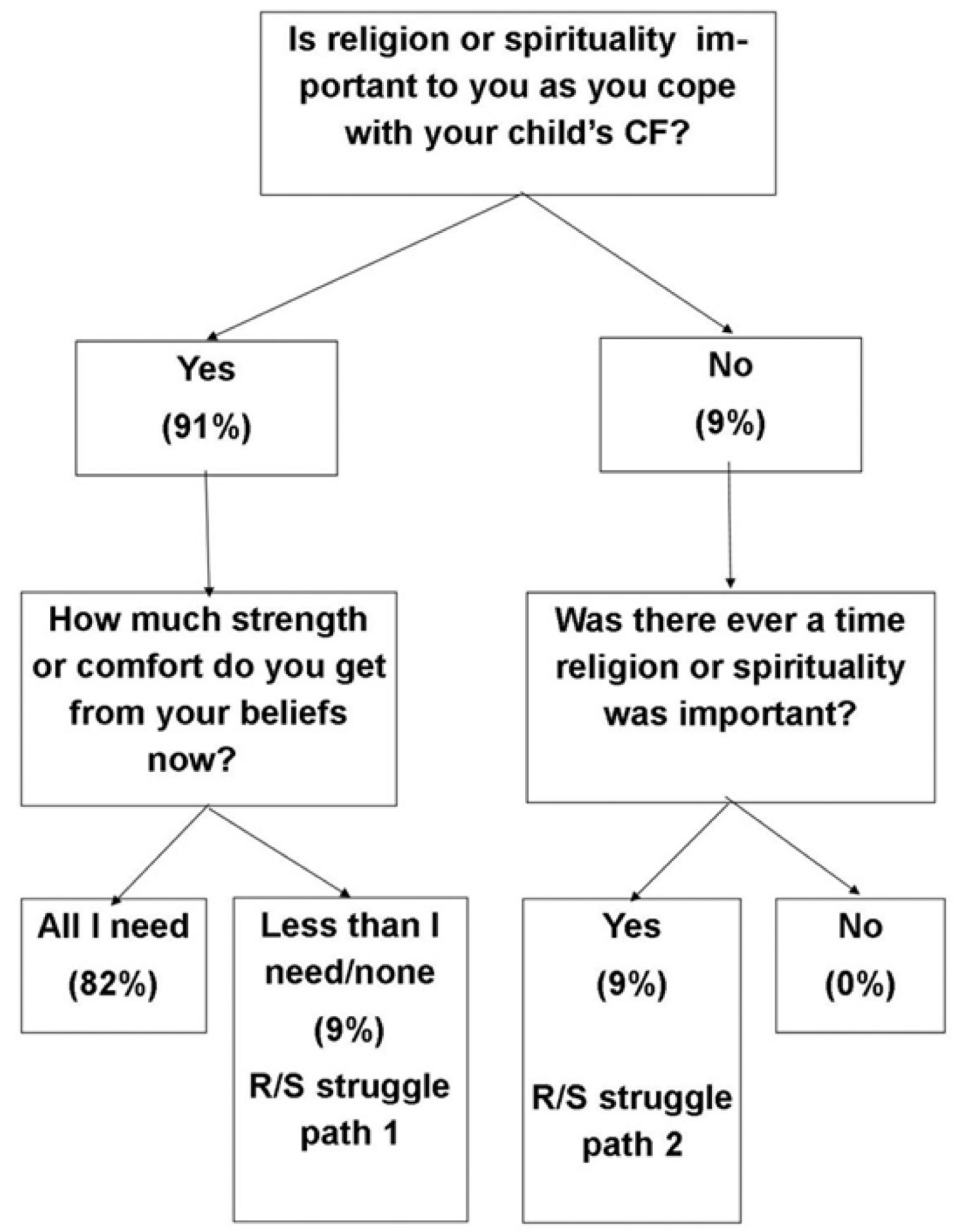

Figure 2.

Spiritual Struggle among CF Parents $(\mathrm{n}=22)$ 
Table 1

Demographic Characteristics of the Sample and Their Children

\begin{tabular}{|c|c|c|c|c|}
\hline & & & $\underset{(\%)}{n}$ & $\begin{array}{c}\text { Mean } \\
\text { (SD) }\end{array}$ \\
\hline \multicolumn{5}{|l|}{ Parents } \\
\hline & Gender & Female & $17(68)$ & \\
\hline & \multirow[t]{2}{*}{ Ethnicity } & Caucasian (non-Hispanic) & $20(92)$ & \\
\hline & & African-American & $2(8)$ & \\
\hline & \multirow[t]{6}{*}{ Age (years) } & $18-25$ & $1(4.5)$ & \\
\hline & & $26-30$ & $4(18.2)$ & \\
\hline & & $31-35$ & $10(45.5)$ & \\
\hline & & $36-40$ & $3(13.6)$ & \\
\hline & & $41-45$ & $3(13.6)$ & \\
\hline & & 46 and older & $1(4.5)$ & \\
\hline & \multirow[t]{3}{*}{ Religious Affiliation } & Christian & $18(72)$ & \\
\hline & & None/Other & $6(24)$ & \\
\hline & & Jewish & $1(4.5)$ & \\
\hline & \multirow[t]{3}{*}{ Religious coping } & Positive (0-21) & & $10.5(4.5)$ \\
\hline & & Negative (0-21) & & $2.7(3.5)$ \\
\hline & & Negative religious coping, $>=2$ & $7(32)$ & \\
\hline & Depressive symptoms (0-60) & & & $16.6(11.1)$ \\
\hline \multicolumn{5}{|l|}{ Children } \\
\hline & Gender & Female & $14(56)$ & \\
\hline & Age & & & $6.5(4.4)$ \\
\hline \multirow[t]{4}{*}{ Disease severity } & \multirow[t]{4}{*}{ Exacerbations in prior year } & 0 & $11(50)$ & \\
\hline & & 1 & $6(27)$ & \\
\hline & & 2 & $4(18)$ & \\
\hline & & 3 or more & $1(4.5)$ & \\
\hline
\end{tabular}


Table 2

Sensitivity and Specificity of Rush Screening Protocol (both pathways)

\begin{tabular}{crcc}
\hline & \multicolumn{2}{c}{ Negative Religious Coping Score } & \\
\cline { 2 - 3 } Rush Screening Protocol Results & Any (ㄹ) & None (0/1) & Total \\
Possible Struggle & $2(9 \%)$ & $2(9 \%)$ & 4 \\
& TP & FP & \\
No Struggle & $5(23 \%)$ & $13(59 \%)$ & 18 \\
& FN & TN & \\
Total & 7 & 15 & 22 \\
\hline
\end{tabular}

Note . $\mathrm{TP}=$ True Positive FP $=$ False Positive $; \mathrm{FN}=$ False Negative $; \mathrm{TN}=$ True Negative. 


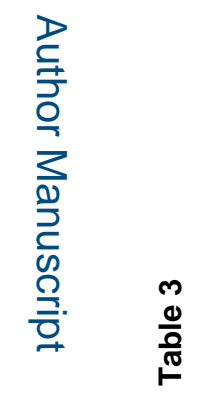

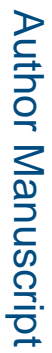

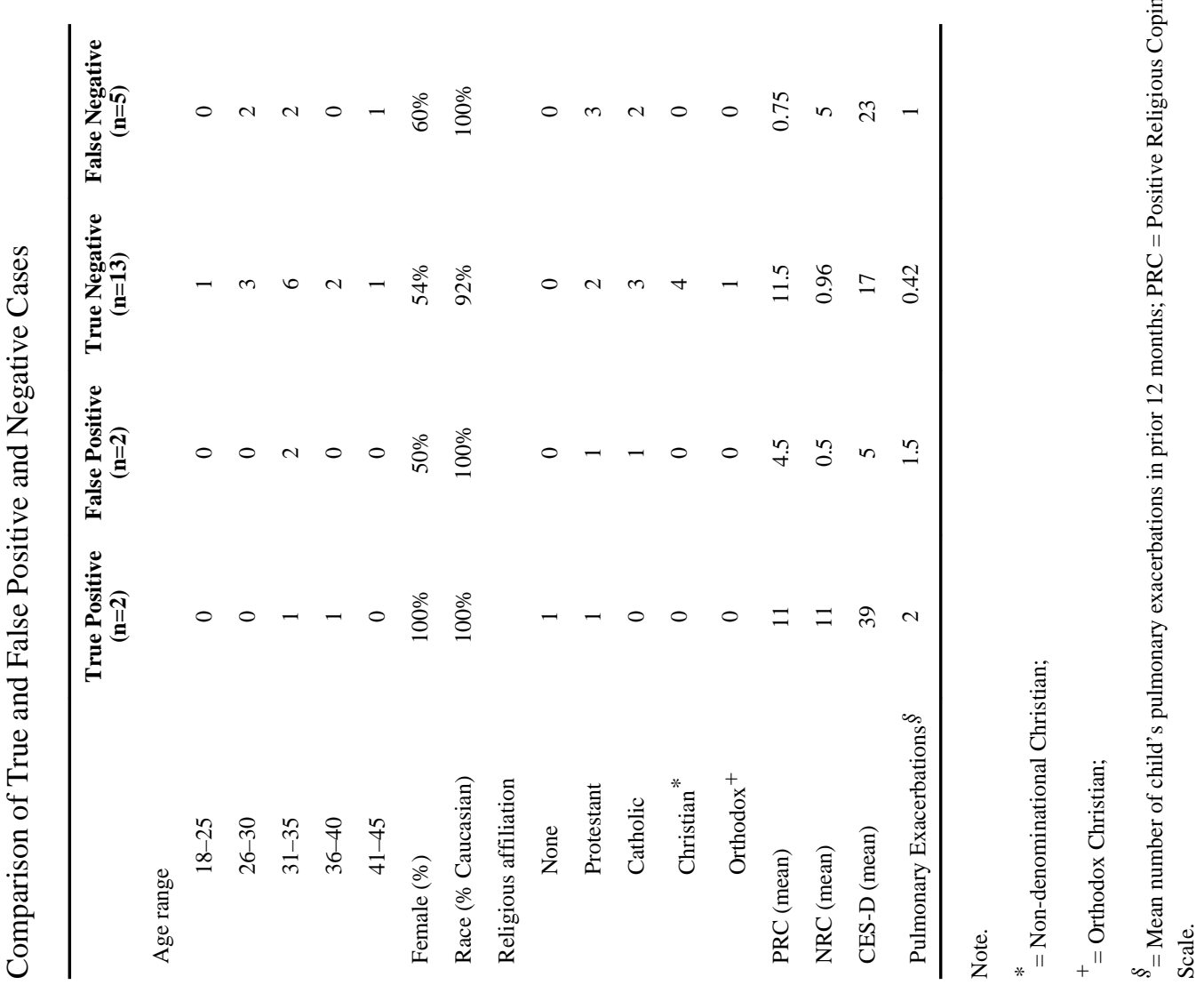

Res Soc Sci Study Relig. Author manuscript; available in PMC 2016 March 08. 